\title{
On the emergence of an MFN club: equal treatment in an unequal world*
}

\author{
Kamal Saggi ${ }^{\dagger}$ and Faruk Sengul ${ }^{\ddagger}$ \\ Department of Economics \\ Southern Methodist University \\ Dallas, TX 75275-0496
}

April 20, 2006

\begin{abstract}
Motivated by GATT, we endogenize the formation of a club whose members have to abide by the MFN principle of non-discrimination. The underlying model is that of oligopolistic intraindustry trade. While an MFN club does not alter average tariff levels across countries, it increases aggregate world welfare; makes non-members worse off; and may even immiserize its high cost members. These results imply that $(i)$ the core WTO rules such as MFN are valuable even if multilateral negotiations deliver limited trade liberalization and $(i i)$ the distributional effects of MFN maybe one reason why developing countries have often been exempted from this rule.
\end{abstract}

Keywords: Most Favored Nation Clause, Welfare, Tariff Discrimination, GATT, Club Formation. JEL Classifications: F13, F10, F15.

\footnotetext{
*We thank Bernard Hoekman, Saltuk Ozerturk, Santanu Roy, Bob Staiger, Halis M. Yildiz, two anonymous referees, and seminar audiences at SMU and a session of the Southern Economics Association meetings in Washington, D.C, 2005 for helpful comments. All errors are our own.

†Phone: (214) 768 3274; E-mail: ksaggi@smu.edu.

‡Phone: (214) 768 2245; E-mail: fsengul@smu.edu.
} 


\section{Introduction}

Throughout the history of the General Agreement on Tariffs and Trade (GATT) and the World Trade Organization (WTO), there have been rounds of negotiations during which member countries have attempted to reduce their trade barriers on each other. However, in several influential papers, Rose (2004a, 2004b) has made the provocative argument that despite such efforts, there is very little evidence that the GATT/WTO has made a significant contribution in promoting world trade. More specifically, in Rose (2004a), he shows that membership in the GATT/WTO is not associated with enhanced trade, once one takes into account standard factors that help explain international trade flows (such as those captured in a typical gravity equation model). The question then becomes why this might be so. Using more than sixty measures of trade policy, Rose (2004b) argues that this is because trade policies of WTO members do not significantly differ from those of non-members. Furthermore, he finds that a country's trade liberalization significantly lags its entry into GATT and that many countries that were relatively closed at the time of their GATT entry remained so for long periods of time. ${ }^{1}$ Evidence regarding early GATT rounds also supports this argument. For example, it is well known that except for the Geneva round of 1947, initial GATT rounds failed to deliver any significant trade liberalization. As Irwin (2002) notes "... after Geneva there was a long period in which relatively little was accomplished. Subsequent negotiating rounds were held at Annecy (1949), Torquay (1950-51), and Geneva (1955-56). These negotiations resulted in the accession of more countries to GATT, but further tariff reductions were negligible, about 2 percent in each round, on average. The Dillon Round (1960-61) also produced little in terms of tangible results."

For those who believe that the GATT/WTO system has been a major factor in promoting world trade, the findings of Rose (2004a and 2004b) are puzzling to say the least. One way to proceed forward is to ask: What, besides trade liberalization, can the WTO system do for world trade? As Rose (2004a) himself suggests,

\footnotetext{
${ }^{1}$ More specifically, Rose (2004b) finds that the openness ratio (i.e. exports plus imports divided by gross domestic product) of a typical accession country five years prior to its joining GATT equals $73.1 \%$ which does not differ significantly from its openness ratio five years post accession (which equals $70.4 \%$ ). In fact, the same is true of all nine measures of trade policy used in his empirical analysis.
} 
the institutional features of the WTO might provide significant benefits to its members and the world as a whole. Our argument in this paper is that by requiring member countries to abide by several key rules specified in its various multilateral agreements such as GATT, the WTO has had an important effect on the policy environment under which international trade occurs. While multilateral trade agreements are quite complicated and contain a multitude of clauses, it is widely acknowledged that the most favored nation (MFN) clause is the fundamental idea underlying all such agreements (see Hoekman and Kostecki, 2001). ${ }^{2}$ What is MFN? As per Jackson (1997): "The MFN obligation calls for each contracting party $(\mathrm{CP})$ to grant to every other $\mathrm{CP}$ the most favorable treatment that it grants to any other country." In other words, MFN requires that each member's tariffs on similar products exported to its market by other members be equal.

In our view, useful insights regarding the role of GATT/WTO system in world trade can be achieved by analyzing GATT as a club whose only requirement for membership is that its members grant MFN to each other. Following this view, it is worthwhile to analyze how such a club might arise and what its welfare effects might be. Accordingly, we endogenize the formation of an MFN club in an environment that abstracts from explicit tariff negotiations amongst its members. ${ }^{3}$ More specifically, we address several questions that arise in this context: From an individual country's perspective, what are the costs and benefits of joining an MFN club? Are all countries willing to join? Does the formation of such a club raise aggregate world welfare? How does it affect the welfare of members and non-members? To answer these and related questions, we examine two different games of club formation between four countries engaged in oligopolistic intraindustry trade of the type formulated in Brander and Krugman (1983). We use this model because it facilitates the analysis of endogenous tariffs in an environment of asymmetry.

The existence of cost asymmetry in our model generates incentives for tariff

\footnotetext{
${ }^{2} \mathrm{MFN}$ constitutes the very first Article of GATT and occupies a central place in the other major multilateral agreements of the WTO such as the General Agreement on Trade in Services and the Agreement on Trade Related Aspects of Intellectual Property Rights.

${ }^{3}$ It is worth emphasizing that tariffs are the only means of protection in our model and should be interpreted as a rough measure of market access. This is important because while tariffs have been substantially reduced over time and some of this progress (and some might say most of it) has been undone by the proliferation of non-tariff barriers to international trade.
} 
discrimination which in turn creates a meaningful role for MFN. It is well established that in an environment of imperfect competition, tariff discrimination is socially harmful when it is biased against low cost exporters (see Gatsios, 1990, Hwang and Mai, 1991, Choi, 1995, Saggi, 2004, and Saggi and Yildiz, 2005). ${ }^{4}$ It follows then that the desirability of an MFN club from a global welfare perspective depends upon how it alters the global distribution of tariffs relative to that under tariff discrimination. Taking this argument as a starting point, we analyze two different games of club formation: $(i)$ an open membership (OM) game and (ii) an exclusive membership (EM) game. We allow countries to deviate jointly and derive the coalition proof Nash equilibria of these games. Our approach is related to that of Aghion et. al. (2004), Yi (1996), and Burbidge et. al. (1997) all of whom analyze games of coalition formation with externalities. While Aghion et. al. (2004) and Yi (1996) focus on the endogenous formation of trade agreements (under which members impose zero tariffs on each other), we primarily consider clubs where members exchange MFN status with one another. Later in the paper, we briefly discuss the case of a free trade club.

We find that the emergence of an MFN club enhances aggregate world welfare and the larger the club, the more desirable it is from a welfare perspective. It is noteworthy that this result obtains even though the emergence of an MFN club does not affect average tariff levels across countries in our model. This implies that adoption of the central WTO rule (i.e. MFN) by its members is of value even when it is not accompanied by any trade liberalization. Furthermore, we show that among clubs that have the same number of members, those that include low cost countries are more desirable because such countries face relatively higher tariffs under discrimination. Thus, the fact that most of the initial GATT members were advanced industrialized countries was probably a good thing.

Given that there exist myriad differences across countries, it is quite unlikely that a non-discrimination requirement such as MFN affects all countries in a similar fashion (even as it increases aggregate welfare). We find that the desirability of an MFN club from a country's perspective depends upon how its production

\footnotetext{
${ }^{4}$ Important contributions to the literature on MFN that are not based on the oligopoly trade model include: Bagwell and Staiger (1999 and 2004), Caplin and Krishna (1988), Ederington and McCalman (2003), Ludema (1991), Maggi (1999), McCalman (2002), and Takemori (1994). See Horn and Mavroidis (2001) for a survey.
} 
cost relative to others. In general, receiving MFN from others is of greater value to countries that have relatively lower costs of production. In fact, we argue that effect that an MFN club has on higher cost countries in our model can shed light on the actual experience of developing countries with the multilateral trading system. More specifically, it is noteworthy that developing country members of the WTO have been granted Special and Differential (S\&D) treatment ever since the Generalized System of Preferences (GSP) came into existence in the 1970s. Under S\&D treatment, many developing countries receive preferential tariffs from major industrialized countries. ${ }^{5}$ As per Oyejide (2002): "S\&D provisions are meant to grant developing countries and least developed countries (LDCs) more favorable access to the markets of industrial countries..." and that the existence of such provisions in the GATT/WTO system reflects the idea that "...because of disparities in economic situation and capacities, there are significant differences in the benefits (italics added) that countries reap from the global trading system." Thus, WTO's S\&D provisions allow developing countries to receive better-than-MFN treatment from industrialized countries. Our results suggest that such exceptions to MFN might have been necessary to undo some of the adverse distributional effects created by the formation of an MFN club. ${ }^{6}$

An intriguing result of our model is that a high cost country can voluntarily end up joining an MFN club even though its welfare as a member is lower than that under tariff discrimination. Such a result obtains because the fate of a high cost country as a non-member can be even worse than that as a member. In fact, we show that a three country club can be an equilibrium even when the two higher cost members are worse off relative to discrimination - each would be better off if neither were to join but has an incentive to join if the other does not. This result accords well with the widespread sense of ambivalence among developing country members of the WTO regarding their status in the organization as well as the benefits that the multilateral trading system confers upon them (see Tussie and Lengyel, 2002).

\footnotetext{
${ }^{5} \mathrm{~A}$ second dimension of $\mathrm{S} \& \mathrm{D}$ treatment was that developing countries were often exempt from certain multilateral rules and disciplines. Developments in the Uruguay Round basically ensured that this dimension of S\&D treatment will eventually be phased out.

${ }^{6}$ It is worth noting here that Rose (2004a) finds that the GSP had a significant and positive effect on promoting trade even though the WTO as a whole did not. Thus, the GSP actually mattered and was not merely a superficial gesture on the part of industrialized countries.
} 
The rest of the paper is organized as follows. Section 2 presents the oligopoly model of international trade under tariff discrimination and MFN while section 3 discusses the effects of different types of MFN clubs (taking their existence as a given). Sections 4 and 5 analyze the open membership and the exclusive membership games to study two different ways of endogenizing an MFN club. Section 6 consider the formation of an MFN club whose members must undertake some trade liberalization trade with respect to each other. Section 7 concludes while section 8 constitutes the appendix. All proofs not provided in the text are in the appendix.

\section{Tariffs in the oligopoly trade model}

We begin with a brief description of the underlying trade model and then analyze two different games that endogenize the formation of an MFN club. There are four countries indexed by $i=a, b, c$, or $d$ and two goods: $x$ and $y$. Consumer preferences over the two goods are quasi-linear: $U(x, y)=u(x)+y$ where the numeraire good $y$ is produced under perfect competition with constant returns to scale technology. Good $x$ is produced by a monopolist in each country. We refer to country $i$ 's monopolist as firm $i$. The marginal cost of production of firm $i$ is given by $\zeta_{i}$, where $\zeta_{d} \geq \zeta_{c} \geq \zeta_{b} \geq \zeta_{a}=0$.

Firms compete in quantities (Cournot competition) and make independent decisions regarding how much to sell in each market (i.e. markets are segmented). Firm $j$ faces a specific tariff $t_{j i}$ when exporting to country $i$, where $t_{i i}=0$ for all $i$. Country $i$ 's tariff schedule $\mathbf{t}_{\mathbf{i}} \equiv\left(t_{a i} \ldots t_{d i}\right)^{\prime}$ is a $4 \times 1$ dimensional vector. Denote the tariff schedules of all countries other than $i$ by $\mathbf{t}_{-\mathbf{i}}$ and the matrix of all countries trade policies by $\mathbf{t}$ where $\mathbf{t} \equiv\left(\mathbf{t}_{\mathbf{a}} \ldots . \mathbf{t}_{\mathbf{d}}\right)$. Let $x_{i}=\sum_{j} x_{j i}$, where $j=a, b, c$, or $d$, denote the total output of good $x$ sold in country $i$ and let $x_{-i}=x_{i}-x_{i i}$ denote country $i$ 's total imports of good $x$.

Whether or not an MFN club exists, all countries simultaneously choose their tariff schedules to maximize their own welfare. As is well known, under linear costs and market segmentation, a country's optimal tariff schedule is independent of the tariff schedules of other countries. Lack of interdependence of tariffs is clearly a limitation of our model but one that greatly simplifies the analysis. In the absence of linearity or market segmentation, the model would not have this 
feature. However, most related models make similar assumptions and as Staiger (1995) has noted, it is not clear whether tariffs ought to be treated as strategic substitutes or complements.

From hereon, the dependence of country $i$ 's domestic surplus $S_{i}\left(\mathbf{t}_{\mathbf{i}}\right)$ (defined in equation 2.1 as the sum of consumer surplus and own firm's profits derived from the local market) on the tariffs of other countries is ignored. If country $i$ practices tariff discrimination toward all other countries, it solves:

$$
\underset{\mathbf{t}_{\mathbf{i}}}{\operatorname{Max}} W_{i}(\mathbf{t}) \equiv S_{i}\left(\mathbf{t}_{\mathbf{i}}\right)+\sum_{j \neq i} \pi_{i j}\left(\mathbf{t}_{\mathbf{j}}\right) \text { where } S_{i}\left(\mathbf{t}_{\mathbf{i}}\right) \equiv C S_{i}\left(\mathbf{t}_{\mathbf{i}}\right)+\pi_{i i}\left(\mathbf{t}_{\mathbf{i}}\right)+T R_{i}\left(\mathbf{t}_{\mathbf{i}}\right)
$$

where $C S_{i}$ denotes consumer surplus in country $i$ and is given by

$$
C S_{i}=u\left(x_{i}\right)-p_{i} x_{i},
$$

$\pi_{i i}\left(\mathbf{t}_{\mathbf{i}}\right)$ denotes the profit function of firm $i$ in its own market and $\sum_{j \neq i} \pi_{i j}\left(\mathbf{t}_{\mathbf{j}}\right)$ denotes its profit function for exports where

$$
\pi_{i i}=\left(p_{i}-\zeta_{i}\right) x_{i i} \text { and } \pi_{i j}=\left(p_{j}-\zeta_{i}-t_{i j}\right) x_{i j}
$$

and $T R_{i}\left(\mathbf{t}_{\mathbf{i}}\right)$ denotes country $i$ 's total tariff revenue:

$$
T R_{i}=\sum_{j \neq i} t_{j i} x_{j i}
$$

The welfare function in (2.1) includes export profits $\sum_{j \neq i} \pi_{i j}\left(\mathbf{t}_{\mathbf{j}}\right)$ because they contribute to domestic welfare (even though market segmentation implies that export profits are independent of a country's own tariffs).

Let $\mathbf{t}_{\mathbf{i}}^{*}$ denote country $i$ 's optimal discriminatory tariff schedule:

$$
\mathbf{t}_{\mathbf{i}}^{*} \equiv \arg \max W_{i}\left(\mathbf{t}_{\mathbf{i}}\right)=\arg \max S_{i}\left(\mathbf{t}_{\mathbf{i}}\right)
$$

If country $i$ practices MFN toward all others, it imposes a non-discriminatory tariff (say $t_{i}$ ) on all foreign exporters and solves:

$$
\operatorname{Max}_{t_{i}} W_{i}\left(t_{i}\right) \equiv S_{i}\left(t_{i}\right)+\sum_{j \neq i} \pi_{i j}\left(\mathbf{t}_{\mathbf{j}}\right) \text { where } S_{i}\left(t_{i}\right) \equiv C S_{i}\left(t_{i}\right)+\pi_{i i}\left(t_{i}\right)+t_{i} x_{-i}
$$

Let $t_{i}^{M}$ denote country $i$ 's optimal MFN tariff. Before analyzing club formation, we quickly note two results that have been established in the existing literature on MFN: 
- Result 1: $t_{j i}^{*} \geq t_{k i}^{*}$ iff $\zeta_{k} \geq \zeta_{j}$ and $t_{j i}^{*} \geq t_{i}^{M}$ iff $\zeta_{j} \leq \frac{\sum_{k \neq i} \zeta_{k}}{3}$.

- Result 2: Under linear demand, $T_{i} \equiv \sum_{j \neq i} t_{j i}^{*}=3 t_{i}^{M}$.

An immediate corollary of Result 1 in our context is that the highest cost country (i.e. $d$ ) has nothing to gain from joining an MFN club since it faces lower tariffs under discrimination. Result 2 says that the formation of an MFN club does not alter its total protection $T_{i}$ (or average tariffs). Note that in our model, the total volume of a country's imports of good $x$ depends only upon its total protection $T_{i}$ (defined above) and not on the distribution of its tariffs.

We now describe the underlying trade-offs involved in joining an MFN club from the perspective of each country. Furthermore, to make analytical progress on the various questions of interest, we assume that $u(x)$ is quadratic so that demand for good $x$ is linear: $p=\alpha-q$.

\section{How an MFN club affects global tariffs}

In this section, we examine how different types of clubs affect the tariffs of members and non-member countries. As per the definition of MFN, we require that each member of an MFN club treat all other members in a non-discriminatory fashion and no worse than non-members. Note that since country $d$ actually faces higher tariffs under MFN than it does under discrimination, it has nothing to gain from being granted MFN and clubs including country $d$ need not be examined.

\subsection{Protection levels and tariff concessions}

In this section, we report some preliminary results that are instrumental for our core analysis (contained in sections 4 and 5). While these results are quite closely linked to the existing literature on MFN under oligopoly, they have not been formally derived or discussed there.

The variation of total tariff protection across countries is as follows:

Lemma 1: The total tariff protection of country $i$ (under tariff discrimination or any MFN club) is decreasing in its own cost: $\frac{\partial T_{i}}{\partial \zeta_{i}}<0$.

The intuition for this result has to do with the fact that tariffs are used to extract rents in the oligopoly model: since demand is symmetric across countries, 
any given reduction in imports does roughly equal harm to consumer welfare in all countries whereas it results in a greater increase in local profits of domestic firms in lower cost countries (because they enjoy higher mark-ups).

How does an MFN club alter tariffs relative to the status quo? Let $\Delta t_{i j}(m)$ denote the tariff concession received by country $i$ from country $j$ in the MFN club $m$ :

$$
\Delta t_{i j}(m)=t_{i j}(\phi)-t_{i j}(m)
$$

where $\langle\{\phi\}\rangle$ denotes the status quo and $m=\langle\{a b c\}\rangle,\langle\{a b\}\rangle,\langle\{a c\}\rangle$, or $\langle\{b c\}\rangle$. The first point to emphasize is that whether or not a member actually receives tariff concessions (i.e. $\Delta t_{i j}(m)>0$ ) from other members depends upon the distribution of production costs across countries. The following is shown in the appendix:

Lemma 2: In any $M F N$ club $m$, the lowest cost member receives tariff concessions from all other members. In general, the higher the cost of a member, the less likely it is that it receives tariff concessions from other members.

Thus, the exchange of MFN among countries does not always result in all members granting tariff concessions to each other. The proof of Lemma 2 provides conditions under which countries other than $a$ also receive tariff concessions when they join an MFN club. To get some intuition for Lemma 2, suppose $\langle\{a b c\}\rangle$ were the MFN club and consider the tariffs faced by each country relative to $\langle\{\phi\}\rangle$. Recall from Result 1 that country $a$ faces the highest tariffs under $\langle\{\phi\}\rangle$. Under $\langle\{a b c\}\rangle$, country $a$ obtains MFN status from countries $b$ and $c$ and therefore receives tariff concessions from both of them. Similarly, from country $a$ 's perspective, country $b$ is its most efficient partner and so country $b$ must receive a tariff concession from country $a$ when $\langle\{a b c\}\rangle$ obtains. But does country $b$ necessarily receive a tariff concession from country $c$ ? The answer is no. From country $c$ 's perspective, country $a$ is the most efficient exporter and it is the one that necessarily receives a tariff concession. Whether country $b$ also receives a tariff concession from country $c$ depends upon the distribution of production costs when country $b$ 's cost is lower than the average of countries $a$ and $d$, it receives a tariff concession from country $c$ or else it suffers a tariff increase from country $c$.

The second key point to establish is that the magnitude of tariff concessions involved in an MFN club are asymmetric in nature: 
Lemma 3: In any $M F N$ club $m$, the tariff concession member $i$ receives from member $j$ is larger than the tariff concession it grants to member $j$ iff its own production cost is relatively lower: $\Delta t_{i j}(m) \geq \Delta t_{j i}(m)$ iff $\zeta_{i} \leq \zeta_{j}$.

Since the lowest cost country faces the highest tariffs under $\langle\{\phi\}\rangle$, the formation of an MFN club forces other members to substantially reduce their tariffs on country $a$. Furthermore, recall that the total protection of a country decreases with own cost (Lemma 1). Also, the least cost and the highest cost countries (i.e. $a$ and $d$ ) do not have as strong an incentive to tariff discriminate as the intermediate countries (i.e. $b$ and $c$ ) who are served by foreign exporters with bigger cost differentials. Therefore, country $a$ 's cost of joining the club is not as high as that of others due to three reasons: $(i)$ it is forced to lower its tariffs less than higher cost countries; ( $(i i)$ the tariff reductions it grants to others apply to a smaller volume of imports due to its higher total protection $T_{i}$ and (iii) it does not suffer as much as intermediate countries from not being able to tariff discriminate.

\subsection{Costs and benefits of joining an MFN club}

Due to strategic independence of tariffs and segmentation of markets, the trade-off underlying a country's decision to join an MFN club is quite transparent: the cost of membership is the loss in domestic surplus that results from not being able to tariff discriminate whereas the benefit is the (potential) increase in export profits generated by the tariff concessions received from other club members. Given Result 2, MFN adoption only lowers the tariff revenue collected by a country without affecting its domestic surplus in other ways. Of course, the extent of revenue reduction depends upon who else joins the club.

Let $\Delta T R_{i}(m)$ measure the reduction in country $i$ 's tariff revenue when it joins the MFN club $m$ where $m=\langle\{a b c\}\rangle,\langle\{a b\}\rangle,\langle\{a c\}\rangle$, or $\langle\{b c\}\rangle$. We have:

$$
\Delta T R_{i}(m)=T R_{i}(\phi)-T R_{i}(m)
$$

The benefit to country $i$ of joining club $m$ is measured by the total increase in its export profits that results from any tariff concessions that accompany membership:

$$
\Delta \pi_{i}(m)=\sum_{j \neq i} \pi_{i j}(m)-\sum_{j \neq i} \pi_{i j}(\phi)
$$


Our first major result describes how the cost of membership depends upon the distribution of production costs across countries and the nature of the MFN club:

Proposition 1: For any two member MFN club, the loss in tariff revenue relative to $\langle\{\phi\}\rangle$ is larger for the higher cost member: $\Delta T R_{j}(m) \geq \Delta T R_{i}(m)$ iff $\zeta_{i} \leq$ $\zeta_{j}$ where $m=\langle\{a b\}\rangle,\langle\{a c\}\rangle$, or $\langle\{b c\}\rangle$. In $\langle\{a b c\}\rangle$, the loss in tariff revenue of the lowest cost member is the smallest: $\Delta T R_{a}(a b c) \leq \min \left\{\Delta T R_{b}(a b c), \Delta T R_{c}(a b c)\right\}$.

The explanation for why the tariff revenue loss of countries $b$ and $c$ cannot be ranked unambiguously has to do with the conflict between the three effects described at the end of section 3.1. While country $b$ loses relatively more from not being able to tariff discriminate, country $c$ reduces its tariffs to a greater degree while also facing a larger volume of imports. How does a country rank two potential partners from the perspective of loss in own tariff revenue?

Lemma 4: From member $i$ 's perspective, a two country club with member $j$ implies a larger loss in tariff revenue than a club with member $k$ iff member $j$ is relatively lower cost than member $k: \Delta T R_{i}(i j) \geq \Delta T R_{i}(i k)$ iff $\zeta_{j} \leq \zeta_{k}$.

The reason for this result is two-fold: not only does country $i$ grant a larger tariff concession to country $j$ under $\langle\{i j\}\rangle$ than it grants country $k$ under $\langle\{i k\}\rangle$ (because $\zeta_{j} \leq \zeta_{k}$ ), the larger concession also applies to a larger volume of imports since $x_{j i}(i j)>x_{k i}(i k)$.

Consider now the benefits received from different potential club partners from the perspective of a country:

Lemma 5: From member $i$ 's perspective, a club with member $j$ yields a larger tariff concession from its partner than does a club with member $k$ iff member $j$ is relatively lower cost than member $k: \Delta t_{i j}(i j) \geq \Delta t_{i k}(i k)$ iff $\zeta_{j} \leq \zeta_{k} \cdot{ }^{7}$

However, a larger tariff concession from country $j$ does not necessarily translate into a larger increase in total export profits for country $i$ since its volume of exports also vary across its trading partners. In fact, from Lemma 1 and the second part of Result 1 , we know that $x_{i k}(i k) \geq x_{i j}(i j)$ iff $\zeta_{j} \leq \zeta_{k}$ - i.e. country $i$ exports more to a relatively higher cost club partner. Since the volume effect counteracts the tariff concession effect, country $i$ 's benefit of club $\langle\{i j\}\rangle$ can be either higher or lower than the benefit of club $\langle\{i k\}\rangle$. On the other hand, the asymmetric nature of tariff concessions involved in an MFN club give us a clear result regarding the

\footnotetext{
${ }^{7}$ In fact, even under the club $\langle\{a b c\}\rangle$ it is true that $\Delta t_{i j}(i j) \geq \Delta t_{i k}(i k)$ iff $\varsigma_{j} \leq \varsigma_{k}$.
} 
distribution of gains that across its members since lemmas 2 and 3 immediately imply:

Proposition 2: For any MFN club $m$, the increase in export profits enjoyed by member $i$ is higher than the corresponding increase for member $j$ iff member $i$ is relatively lower cost than member $j: \Delta \pi_{i}(m)>\Delta \pi_{j}(m)$ iff $\zeta_{i} \leq \zeta_{j}$.

An immediate implication of Propositions 1 and 2 is that country $a$ has the strongest incentive to join an MFN club: it suffers the lowest decline in tariff revenue and enjoys the highest increase in export profits. In fact, it would like to form an MFN club with whoever else is willing to do so. The following proposition compares various MFN clubs from each country's perspective:

Proposition 3: Let $\succ_{i}$ denote strict preference and $\sim_{i}$ indifference for country $i$. The following hold with respect to individual country rankings of the various MFN clubs: (i) country a: $\langle\{a b c\}\rangle \succ_{a}(\langle\{a c\}\rangle,\langle\{a b\}\rangle) \succ_{a}\langle\{\phi\}\rangle \sim_{a}\langle\{b c\}\rangle$; (ii) country b: $\langle\{b c\}\rangle \succ_{b} \phi \succeq_{b}\langle\{a c\}\rangle$ and (iii) country $c:\langle\{b c\}\rangle \succ_{c}\langle\{a c\}\rangle$.

Part $(i)$ of proposition 3 follows from Lemmas 2 and 3: country a receives relatively large tariff concessions from all others that join and therefore likes the biggest MFN club the best. Perhaps more intriguing is the fact that country $a$ does not have an unambiguous preference between the clubs $\langle\{a c\}\rangle$ and $\langle\{a b\}\rangle$. Why is this so? The answer is contained in Lemmas 4 and 5: while country a receives a bigger tariff concession from country $b$ under $\langle\{a b\}\rangle$ than it does from country $c$ under $\langle\{a c\}\rangle$, it also has to grant country $b$ a bigger concession relative to what it has to grant country $c$. Finally, why is country $a$ indifferent between $\langle\{b c\}\rangle$ and $\langle\{\phi\}\rangle$ ? Result 2 says that the total protection of each member does not change relative to $\langle\{\phi\}\rangle$ when $\langle\{b c\}\rangle$ is formed. Since country $a$ has the lowest production cost, country $b$ imposes its optimal discriminatory tariff on it while imposing the average of its optimal discriminatory tariffs on the other two countries. Exactly an analogous argument applies to country c's tariff schedule under $\langle\{b c\}\rangle$. As a result, the sum total of tariff included marginal costs of rival exporters faced by country $a$ under $\langle\{b c\}\rangle$ is the same as that under $\langle\{\phi\}\rangle$. Since its own domestic surplus does not change due to the formation of $\langle\{b c\}\rangle$, country $a$ is strictly indifferent between $\langle\{\phi\}\rangle$ and $\langle\{b c\}\rangle$.

While a general ranking of country b's preferences among the various clubs is not possible, it turns out that for most parameter values it prefers $\langle\{b c\}\rangle$ to $\langle\{a b\}\rangle$. Only when country $b$ itself is relatively low cost does it find $\langle\{a b\}\rangle$ more 
attractive than $\langle\{b c\}\rangle$. Country $c$, on the other hand, always prefers $\langle\{b c\}\rangle$ to $\langle\{a c\}\rangle$. As is clear from Lemma 2, as the production cost of a country increases, its incentive to exchange MFN with the lowest cost country declines.

How are non-members affected by the formation of an MFN club? The answer here is clear - non-members are (weakly) worse off relative to tariff discrimination since tariffs of members on non-members are never lower than those under discrimination whereas their tariffs on other members are no higher than those on non-members. Note that under $\langle\{a b c\}\rangle$ country $c$ can face higher tariffs than that under $\langle\{\phi\}\rangle$ and still remain in the club since the tariffs it faces under $\langle\{a b\}\rangle$ would be still higher.

It is easy to show that the bigger the MFN club, the higher is aggregate world welfare (defined as the sum of the welfare of individual countries). This implies that the most desirable MFN club - i.e. $\langle\{a b c d\}\rangle$ - does not arise because country $d$ is always better off as a non-member. Of the remaining clubs, $\langle\{a b c\}\rangle$ is clearly the next best option. But what about clubs $\langle\{a b\}\rangle,\langle\{a c\}\rangle$, and $\langle\{b c\}\rangle$ ? Here, the result is as follows:

Proposition 4: Among MFN clubs with only two members, $\langle\{a b\}\rangle$ yields the highest aggregate world welfare while $\langle\{b c\}\rangle$ yields the lowest.

The inclusion of country $a$ in an MFN club is of vital importance for world welfare because the large tariff reductions it receives in other markets help allocate more of the world's production to the lowest cost location. Similarly, since country $b$ is lower cost than $c$, its inclusion in an MFN club is relatively more important. As a result, $\langle\{a b\}\rangle$ is welfare-preferred to $\langle\{a c\}\rangle$. The club $\langle\{b c\}\rangle$ excludes the lowest cost producer who ends up facing the same tariffs as it does under $\langle\{\phi\}\rangle$ and is therefore of least value (although it is still preferable to $\langle\{\phi\}\rangle$ because it allocates output in favor of countries $b$ and $c$ at the expense of country $d$ ).

Having described how various types of MFN clubs affect tariffs and welfare, we are now ready to endogenize club formation.

\section{An open membership MFN club}

In this section, we analyze an open membership $(\mathrm{OM})$ game that captures the following intuitive scenario that can be viewed as the 'beginning of GATT'. Imagine that there is a room (call it the MFN club) upon entering which a country has to 
grant MFN to all those that have entered as well (in case it decides to stay in the club). Each country is free to enter or leave the club. Countries that choose not to enter practice tariff discrimination and do not receive MFN status from those inside the club. An MFN club obtains in equilibrium if several countries enter the room and decide to stay.

The above game is formalized as follows. In the first stage, countries simultaneously decide whether or not to adopt MFN with respect to their tariff schedules. Each country makes an announcement: it either commits to MFN or not. After countries make their announcements, each country that commits to MFN grants MFN status to all others countries that make same commitment. Next, given their policy regimes, all countries simultaneously choose their tariff schedules. Finally, firms choose their output levels.

It is easy to see that the OM game admits multiple (sub-game perfect) Nash equilibria - no country would stay in the MFN club as a singleton. As a result, status quo is a Nash equilibrium of the OM game but it is not a very interesting one. Furthermore, it seems desirable to allow countries to form coalitions and deviate jointly from any outcome. When such deviations are possible, a more appropriate equilibrium concept is that of a coalition proof Nash equilibrium. Intuitively, a Nash equilibrium is coalition-proof if it is immune to credible or self-enforcing coalitional deviations. ${ }^{8}$ However, in the OM game, under minor conditions all Nash equilibria turn out to be coalition-proof (shown in the appendix). The reason for this is as follows. It is meaningful to examine coalitional deviations only when $\langle\{a b c\}\rangle$ emerges as the club. Furthermore, the only deviation to consider from $\langle\{a b c\}\rangle$ is the joint deviation of countries $b$ and $c$ to $\langle\{\phi\}\rangle \cdot{ }^{9}$ However, under minor conditions, this deviation is not credible since each deviating country wants to further deviate to form a club with country a alone. This argument is easy to see from Figure 1 which illustrates equilibrium MFN clubs in the OM game in the $\left(\zeta_{b}, \zeta_{c}\right)$ space.

- Figure 1 here -

\footnotetext{
${ }^{8}$ See Bernheim and Whinston (1987a and 1987b) for further details.

${ }^{9}$ Country $a$ is free to enter the club and will always do so. Thus, when acting jointly, countries $b$ and $c$ can only leave the club together (i.e. cannot form a club by themselves). By contrast, under the exclusive membership game analyzed below, countries $b$ and $c$ have the ability to exclude country $a$ from the club and coalitional deviations are more interesting there.
} 
In Figure 1, only the region above the 45 degree line is relevant since $\zeta_{c} \geq$ $\zeta_{b} \cdot{ }^{10}$ By using indifference conditions for all countries, the parameter space can be partitioned into regions over which various clubs obtain in equilibrium. For example, along the curve $c: a c=\phi$ country $c$ is indifferent between clubs $\langle\{a c\}\rangle$ and $\langle\{\phi\}\rangle$; below the curve it prefers $\langle\{a c\}\rangle$ to $\langle\{\phi\}\rangle$ whereas the opposite is true above it. All other indifference curves are labelled similarly - the identity of a country is followed by the regimes among which it is indifferent along a particular indifference curve. The intuition for why indifference curves slope upwards is that granting MFN to an efficient country is costly in terms of foregone tariff revenue whereas receiving MFN is attractive precisely when own cost is low. For example, for country $c$ to remain indifferent between being part of a club versus being outside, an increase in its own cost has to be matched by an increase in the cost of country $b$.

Several important conclusions emerge from Figure 1: (i) Over much of the parameter space, $\langle\{a b c\}\rangle$ and $\langle\{a b\}\rangle$ emerge as MFN clubs. In other words, an equilibrium MFN club is more likely to have the lower cost countries as its members; (ii) $\langle\{a b c\}\rangle$ emerges when all countries have relatively similar (and low) costs of production; (iii) when both countries $b$ and $c$ have high costs, no one wants to join country $a$ in an MFN club and $\langle\{\phi\}\rangle$ ends up as the equilibrium; (iv) there is a small region right above region $\mathrm{B}$ in which both $\langle\{a b\}\rangle$ and $\langle\{a c\}\rangle$ are equilibria. Note that this region is close to the 45 degree line - i.e. when countries $b$ and $c$ have very similar costs, only one of them ends up as a member; and $(v)$ the region over which $\langle\{a b c\}\rangle$ obtains club can be divided into three sub-regions: $\mathrm{A}, \mathrm{B}$, and C. In sub-region C, all countries prefer $\langle\{a b c\}\rangle$ to $\langle\{\phi\}\rangle$. However, this is not the case in the other two sub-regions. In sub-region $\mathrm{B}$, country $b$ prefers $\langle\{\phi\}\rangle$ to $\langle\{a b c\}\rangle$ but opts to join the club because it is worse off under $\langle\{a c\}\rangle$ than it is under $\langle\{\phi\}\rangle$. Furthermore, in both sub-regions A and B, country $c$ prefers $\langle\{\phi\}\rangle$ to $\langle\{a b c\}\rangle$ but it ends up in the club because its welfare as member of $\langle\{a b c\}\rangle$ is higher than that under $\langle\{a b\}\rangle$ as a non-member. The last result deserves emphasis:

\footnotetext{
${ }^{10}$ Parameter values are $\zeta_{d}=1$ and $\alpha=20$. Also recall that $\zeta_{a}=0$ through-out the model.
} 
Proposition 5: The MFN club $\langle\{a b c\}\rangle$ can arise in equilibrium even though its relatively high cost members (i.e. countries $b$ and c) are worse off relative to $\langle\{\phi\}\rangle$. Furthermore, if country $b$ is worse off under $\langle\{a b c\}\rangle$ then country $c$ must also be worse off.

Proposition 5 obtains because a country can end up joining an MFN club not because it prefers joining the club to $\langle\{\phi\}\rangle$ but rather because being a nonmember is worse than being a member. But can't countries $b$ and $c$ prevent such an outcome by jointly deviating to $\langle\{\phi\}\rangle$ as a coalition? The answer to this question turns out to be no. If they were to deviate to $\langle\{\phi\}\rangle$ together, then each would want to further deviate from that to form an MFN club with country $a$ alone. As a result, the coalitional deviation of countries $b$ and $c$ to $\langle\{\phi\}\rangle$ is not credible. ${ }^{11}$

The cost asymmetry between countries is crucial in delivering proposition 5 . This result can perhaps shed some light on the widespread sense of dissatisfaction among the WTO's developing country members. Proposition 5 indicates that it is the higher cost countries that can end up being reluctant members of an MFN club and the higher a country's cost, the more likely it is that it loses as a member relative to $\langle\{\phi\}\rangle .^{12}$

Since it is a dominant strategy for country $a$ to enter the MFN club, $\langle\{b c\}\rangle$ is not an equilibrium of the OM game. Thus, an attractive feature of the OM game is that the least desirable MFN club does not obtain. In the OM game, if country $j$ no longer wishes to be in a club if another (say country $k$ ) joins the only option open to country $j$ is to itself leave the club - it cannot unilaterally exclude any other country from joining the club. Given this, it seems reasonable to also consider a game where a subset of countries can indeed exclude others from the club if they benefit from doing so. In a simultaneous move game, this idea can be captured by the following exclusive membership game.

\footnotetext{
${ }^{11}$ In fact, it is quite possible that a member actually suffers a decrease in export profits when it joins the club relative to $\langle\{\phi\}\rangle$ but ends up joining because its export profits as a non-member are still lower.

${ }^{12}$ In equilibrium, there can be only two MFN clubs with two members: $\langle\{a b\}\rangle$ and $\langle\{a c\}\rangle$. As is clear, neither member of these clubs can be worse off relative to $\langle\{\phi\}\rangle$ since each is free to deviate unilaterally to $\langle\{\phi\}\rangle$.
} 


\section{An exclusive membership MFN club}

In the first stage of the exclusive membership (EM) game, each country makes an announcement regarding the list of potential MFN club members. For example, country $a$ 's strategy set is $S_{a}=\{\langle\{\phi\}\rangle,\langle\{a b\}\rangle,\langle\{a c\}\rangle,\langle\{a b c\}\rangle\}{ }^{13}$ In the next stage, an MFN club is formed by those that make the same announcement. If no announcements match, status quo $\langle\{\phi\}\rangle$ prevails.

In the EM game, whenever a country unilaterally deviates from a three country MFN club, the other two countries remain within the club (as in Hart and Kurz, 1983). Also, any unilateral deviation from a two country club yields the status quo $\langle\{\phi\}\rangle$. Just like the OM game, $\langle\{\phi\}\rangle$ is a Nash equilibrium of the EM game for all parameter values. However, unlike the OM game, Nash equilibria of the EM game are much less likely to be coalition-proof. We illustrate this below by two examples. Let $\Delta w_{i}(m)$ denote the difference between country $i$ 's welfare under club $m$ and status quo $\langle\{\phi\}\rangle: \Delta w_{i}(m) \equiv w_{i}(m)-w_{i}(\phi)$.

Example 1: Suppose $\zeta_{a}=0, \zeta_{b}=0.2, \zeta_{c}=0.6, \zeta_{d}=1$, and $\alpha=20$.

\begin{tabular}{|c|c|c|c|c|}
\hline$\Delta w_{i}(m) \quad$ Country & $a$ & $b$ & $c$ & $d$ \\
\hline 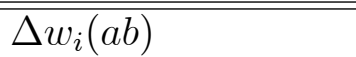 & 0.96 & 0.63 & -0.11 & -1.14 \\
\hline$\Delta w_{i}(a c)$ & 1.06 & 0.00 & 0.20 & -0.98 \\
\hline$\Delta w_{i}(b c)$ & 0.00 & $0.79^{*}$ & $0.26^{*}$ & -0.85 \\
\hline$\Delta w_{i}(a b c)$ & 1.88 & 1.03 & -0.25 & -1.97 \\
\hline
\end{tabular}

In Table 1, row 1 shows that the formation of $\langle\{a b\}\rangle$ increases welfare of member countries and that of the world as a whole whereas it lowers the welfare of non-members. It is easy to verify that in Table 2, there are three Nash equilibria (in addition to $\langle\{\phi\}\rangle):\langle\{a b\}\rangle,\langle\{a c\}\rangle,\langle\{b c\}\rangle$. The club $\langle\{a b c\}\rangle$ fails to be a Nash equilibrium because country $c$ is better off under $\langle\{\phi\}\rangle$ and would unilaterally deviate from $\langle\{a b c\}\rangle$ to leave the club. Of the three Nash equilibria, only $\langle\{b c\}\rangle$ is coalition-proof - this is indicated in Table 1 by the superscript ${ }^{*}$ on the payoffs of club members. For example, $\langle\{a c\}\rangle$ is not coalition-proof because countries $b$

\footnotetext{
${ }^{13}$ The club $\langle\{a b c d\}\rangle$ need not be considered because country $d$ never wants to join an MFN club.
} 
and $c$ can raise their individual welfare levels by jointly deviating to $\langle\{b c\}\rangle$. Furthermore, this joint deviation is credible because neither country has a unilateral incentive to further deviate from $\langle\{b c\}\rangle$. Similar arguments can establish $\langle\{a b\}\rangle$ and $\langle\{\phi\}\rangle$ are also not coalition-proof.

Example 2: Now suppose $\zeta_{a}=0, \zeta_{b}=0.2, \zeta_{c}=0.4, \zeta_{d}=1$, and $\alpha=20$. Here, all parameters are the same as that in example 1 except that $\zeta_{c}$ is lower.

Table 2: All clubs are Nash but only $\{a b c\}$ and $\{b c\}$ are coalition-proof

\begin{tabular}{|l||cccc|}
\hline \multicolumn{1}{|c||}{ Country } & $a$ & $b$ & $c$ & $d$ \\
$\Delta w_{i}(m)$ & & & & \\
\hline \hline$\Delta w_{i}(a b)$ & 0.95 & 0.63 & 0.12 & -1.21 \\
$\Delta w_{i}(a c)$ & 1.01 & 0.00 & 0.40 & -1.07 \\
$\Delta w_{i}(b c)$ & 0.00 & $0.75^{*}$ & $0.46^{*}$ & -0.96 \\
$\Delta w_{i}(a b c)$ & $1.70^{*}$ & $0.88^{*}$ & $0.21^{*}$ & -2.09 \\
\hline
\end{tabular}

Now $\langle\{a b\}\rangle,\langle\{a c\}\rangle,\langle\{b c\}\rangle,\langle\{a b c\}\rangle$ are all Nash equilibria but only $\langle\{a b c\}\rangle$ and $\langle\{b c\}\rangle$ are coalition-proof - as is indicated in Table 2 by the superscript * on the payoffs of club members. Since country c's cost is now relatively lower compared to Example 1, it is a more willing participant in MFN clubs. To see, for example, as to why $\langle\{a b\}\rangle$ fails to be coalition-proof, simply note that countries $b$ and $c$ can jointly deviate to $\langle\{b c\}\rangle$ and improve their welfare.

Figure 2 illustrates Nash equilibria of the EM game while coalition-proof Nash equilibria are shown in Figure 3.

- Figure 2 here -

As is clear from Figure 2, multiplicity of Nash equilibria obtains for almost all feasible parameter values. For example, in sub-region A, $\langle\{a b c\}\rangle,\langle\{a b\}\rangle,\langle\{a c\}\rangle$, and $\langle\{b c\}\rangle$ are all Nash equilibria. Such multiplicity makes it imperative to focus on coalition-proof Nash equilibria (see Figure 3 below).

- Figure 3 here -

Consider a comparison of Figures 1 through 3 in order to grasp the differences between the outcomes obtained under the two games of club formation. The following points emerge from this comparison: 
- The parameter space over which $\langle\{a b c\}\rangle$ is coalition-proof under the EM game is much smaller than the space over which it is a Nash equilibrium.

- The club $\langle\{b c\}\rangle$ is coalition-proof over a large parameter space in the EM game whereas it is never coalition-proof in the OM game. This finding is of particular interest because $\langle\{b c\}\rangle$ is the least desirable MFN club from the viewpoint of world welfare. Why is $\langle\{b c\}\rangle$ coalition-proof for such a large range of parameter values in the EM game? This is because countries $b$ and $c$ benefit substantially from the exclusion of country $a$ to whom they have to grant large tariff concessions as a member (see section 3). To gain more insight into this result, fix country $b$ 's cost at a low level (say close to zero) and consider moving vertically in Figure 3 plotted in the $\left(\zeta_{b}, \zeta_{c}\right)$ space. Near the origin, where each country's cost is small, $\langle\{a b c\}\rangle$ is the equilibrium. Here, no country has an incentive to exclude any other country from the club since everyone is essentially low cost. As country c's cost increases, it has an incentive to exclude country $a$ whereas country $b$ does not. Hence, both $\langle\{b c\}\rangle$ and $\langle\{a b c\}\rangle$ are equilibrium MFN clubs. A further increase in country c's cost makes $\langle\{b c\}\rangle$ the only equilibrium - when country c's cost is really high, country $b$ has a strong incentive to tariff discriminate between $a$ and $c$ (so that it wants to keep country $a$ out of the club) and its tariff on country $c$ is quite low (making $\langle\{b c\}\rangle$ attractive to country $c$ ). And finally, when country $c$ 's cost is almost equal to that of country $d$, the club $\langle\{a b\}\rangle$ emerges as the equilibrium since country $c$ does not gain much from being granted MFN by other countries (i.e. under $\langle\{\phi\}\rangle$ it faces fairly low tariffs).

- The most desirable MFN club (i.e. $\langle\{a b c\}\rangle$ ) is coalition-proof over a smaller region in the EM game relative to the OM game. As noted above, the ability to exclude country $a$ is exercised by countries $b$ and $c$ to keep high tariffs on country $a$. In this respect, the EM game gives a worse outcome than the OM game.

- The club $\langle\{a c\}\rangle$ is never coalition-proof under the EM game since countries $b$ and $c$ have an incentive to jointly deviate to $\langle\{b c\}\rangle$ in order to exclude country $a$.

Ceteris paribus, does the OM game yield outcomes that always dominate those 
yielded by the EM game? The answer to this question is in the affirmative except when both countries $b$ and $c$ have relatively high costs (i.e. there costs are close to that of country $d$ ). Under such a world of one low cost and several high cost countries, no country wants to form a club with country $a$ in the OM game thereby yielding $\langle\{\phi\}\rangle$ as the equilibrium whereas countries $b$ and $c$ want to form $\langle\{b c\}\rangle$ under the EM game since they can exclude country $a$ from the club. While $\langle\{b c\}\rangle$ is the least desirable MFN club, it still yields higher world welfare than $\langle\{\phi\}\rangle$.

Furthermore, compared to the OM game, it is much less likely that an MFN club immiserizes its higher cost members relative to tariff discrimination. More specifically, in the EM game, country $b$ is never worse off as a club member whereas country $c$ is worse off over a much smaller region relative to the OM game (compare region $\mathrm{A}$ in figures 1 and 3 ).

\section{Trade liberalization}

The bulk of our analysis assumes that member countries of an MFN club do not undertake any explicit trade liberalization. In fact, in our model, any trade liberalization that occurs within the club is purely incidental to MFN adoption. As argued in the Introduction of the paper, this is a reasonable approach to analyzing GATT. Nevertheless, it is worth examining a situation where members of an MFN club also undertake trade liberalization towards one another.

Suppose membership of an MFN club requires that members not only adopt MFN but also use a tariff lower than their optimal MFN tariff. More specifically, in club $m$, member country $i$ 's tariff must equal $\theta t_{i}(m)$ where $\theta$ measures the degree of trade liberalization required for membership and $0 \leq \theta \leq 1$. Clearly, when $\theta=0$ we are in the case of a free trade club and when $\theta=1$ the club is purely an MFN one. As might be expected, the analysis under partial trade liberalization (i.e. $0<\theta<1$ ) is significantly more complicated than the polar cases of $\theta=0$ or $\theta=1$. This is because the level of the tariff reductions undertaken by a country depend not only on the distribution of costs across countries but also on the identity of club members. Furthermore, each country has to take this into account when choosing whether or not to enter the club in the OM game and which club to announce in the EM game. As a result, it proves instructive to consider two special cases: $\theta=0$ and $\theta=0.8$. When $\theta=0$, club members 
practice free trade and this case is of obvious interest. The motivation for picking $\theta=0.8$ is that the first GATT round involved a tariff reduction of $20 \%$ on an MFN basis.

When $\theta=0$ our OM game becomes analogous to the game analyzed by $\mathrm{Yi}$ (1996) with two important differences. First, Yi (1996) studies a customs union whereas we consider a free trade club. Second, unlike us, he assumes that countries are symmetric with respect to their production costs. Figure 4 illustrates coalition proof Nash equilibria of the OM game for $\theta=0$.

\section{- Figure 4 here -}

As is clear from Figure 4, trade liberalization indeed matters since global free trade $\langle\{a b c d\}\rangle$ can now emerge as an equilibrium. As might be expected, when club members practice free trade, membership becomes more desirable to all countries. However, global free trade $\langle\{a b c d\}\rangle$ obtains only when the higher cost countries are relatively symmetric in terms of their production costs (i.e. northeast corner of Figure 4). For example, when country $d$ is much higher cost than others (i.e. southwest corner of Figure 4), it opts to stay out and $\langle\{a b c\}\rangle$ obtains in equilibrium. This is in sharp contrast to Yi (1996) where, in equilibrium, all countries end up joining the customs union. Thus, our results imply that even if GATT membership were to provide a country with immediate free access to markets of other member countries (in return for providing such access itself), the very fact that such liberalization occurs on an MFN basis is enough to make membership unattractive to some countries.

In our view, the fact that country $d$ might prefer to stay out of a free trade club strengthens the argument that provisions other than MFN might indeed be necessary to encourage developing countries to participate in the multilateral trading system. But a subtle point is worth stressing here: even when country $d$ stays out of the free trade club, it is better off relative to tariff discrimination. By contrast, in the absence of trade liberalization non-members are always made worse off by the formation of an MFN club. Why is this not true of a free trade club? The reason is that when member countries eliminate tariffs on each other, they also lower them on country $d$ (i.e. there is tariff complementarity). As a result, country $d$ can partially free ride on trade liberalization that occurs among 
others while retaining the right to tariff discriminate itself. Why don't other countries have an incentive to do the same? This is because the welfare gain of membership is higher for relatively efficient producers - recall from Result 1 that optimal discriminatory tariffs are biased against lower cost producers. Thus, those that have lower costs stand to gain more from membership and the temptation to free ride on the liberalization of others is not strong enough for them to remain outside the free trade club.

We now briefly discuss the case of $\theta=0.8$. Here, all countries joining an MFN club undertake a $20 \%$ cut in their optimal MFN tariffs (which of course depend upon who else is in the club). Rather than provide an exhaustive and repetitive analysis we briefly note our main conclusions. Table 3 shows equilibrium outcomes for the case of $\theta=0.8$ for the same parameter values as the ones used to construct Table 2 (i.e. $\alpha=20, \zeta_{b}=.2, \zeta_{c}=.4$ ) where $\theta=1$. In Table 3 , the superscript ** indicates that $\langle\{a b c\}\rangle$ is a coalition proof Nash equilibrium of both games whereas the superscript $*$ indicates that $\langle\{b c d\}\rangle$ is a coalition proof Nash equilibrium of only the EM game. ${ }^{14}$ As is clear from Table 3, when club members reduce their MFN tariffs by $20 \%$ country $d$ is not willing to join the club if country $a$ is also a member since it has an incentive to deviate from $\langle\{a b c d\}\rangle$ to $\langle\{a b c\}\rangle$. Nevertheless, a comparison of Tables 2 and 3 indicates that country $d$ is willing to form a club with countries $b$ and $c$ when $\theta=0.8$ whereas it is not willing to do so when $\theta=1$. Thus, trade liberalization does increase the willingness of country $d$ to be a club member to some degree. Note also that countries $b$ and $c$ are actually better off under $\langle\{a b c d\}\rangle$ relative to $\langle\{b c d\}\rangle$ but country $d$ prevents this outcome. Finally, just as in the case of a free trade club, membership does not immiserize any country in the OM game when it is accompanied by a $20 \%$ reduction in MFN tariffs by all members (as evidenced by the lack of any negative numbers in Table $3)$.

\footnotetext{
${ }^{14}$ If countries $c$ and $d$ are relatively similar, we can obtain $\langle\{a b c d\}\rangle$ under the OM game for the case of $\theta=0.8$.
} 
Table 3: Equilibrium clubs with $20 \%$ tariff cuts (i.e. $\theta=0.8$ )

\begin{tabular}{|l||cccc|}
\hline \multicolumn{1}{|c||}{ Country } & $a$ & $b$ & $c$ & $d$ \\
$\Delta w_{i}(m)$ & & & & \\
\hline \hline$\Delta w_{i}(a b)$ & 2.86 & 2.44 & 1.17 & 0.96 \\
$\Delta w_{i}(a c)$ & 2.96 & 1.21 & 2.12 & 0.96 \\
$\Delta w_{i}(a d)$ & 2.55 & 1.04 & 0.99 & 1.52 \\
$\Delta w_{i}(b c)$ & 1.24 & 2.60 & 2.20 & 0.94 \\
$\Delta w_{i}(b d)$ & 1.10 & 2.51 & 1.00 & 1.52 \\
$\Delta w_{i}(c d)$ & 1.07 & 1.03 & 2.20 & 1.60 \\
$\Delta w_{i}(a b c)$ & $5.06^{* *}$ & $3.91^{* *}$ & $2.87^{* *}$ & 1.46 \\
$\Delta w_{i}(a b d)$ & 5.34 & 4.21 & 1.94 & 0.92 \\
$\Delta w_{i}(a c d)$ & 5.57 & 2.05 & 3.37 & 1.14 \\
$\Delta w_{i}(b c d)$ & 2.13 & $4.77^{*}$ & $3.68^{*}$ & $1.33^{*}$ \\
$\Delta w_{i}(a b c d)$ & 7.54 & 5.78 & 4.19 & 0.73 \\
\hline
\end{tabular}

\section{Conclusion}

This paper analyzes two related games of club formation in order to gain insight into the emergence of various types of MFN clubs and to examine the welfare consequences of such clubs. The underlying trade model is one of oligopolistic intraindustry trade between four countries that are asymmetric with respect to production costs. This simple structure is sufficient to yield a basis for tariff discrimination on the part of individual countries whose tariff policies are constrained upon the adoption of an MFN clause.

We find that the formation of any MFN club increases world welfare even though no such club has an affect on average tariff levels. This implies that WTO rules have value even if rounds of negotiations between WTO members fail to deliver significant trade liberalization. Given the findings of Rose (2004a and 2004b), this result is reassuring for those who think that the WTO has a useful role to play in the arena of international trade. However, one cannot immediately jump from this conclusion to the argument that membership in an MFN club necessarily makes all participating countries better off. In particular, high cost members of the club can lose relative to the status quo even though membership is entirely voluntary. The insight behind this result is that a country may be induced to join a club because being a non-member is worse than being a member. Of course, if 
transfers (or issue linkages) are possible between countries, such an outcome can be avoided since aggregate world welfare is necessarily increased from any type of MFN club. Similarly, trade liberalization amongst club members can also make this outcome unlikely.

Those that do not join the club are necessarily worse off relative to the status quo and they choose remain outside either because membership further immiserizes them or because they are simply excluded by others (as in the exclusive membership game). In the model, the country with the highest production cost never joins an MFN club that involves no explicit trade liberalization and it is always better off in a world where no such club exists. This result might shed some light on the Special and Differential (S\&D) treatment accorded to developing country members of the WTO under which they receive better than MFN treatment under GATT. The model suggests that absence such treatment, many developing countries may prefer to remain outside the GATT/WTO. Since aggregate world welfare is increasing in the size of the MFN club, S\&D provisions might have generated some indirect benefits for the world as a whole (the costs of such distortionary policies notwithstanding).

While our model provides some interesting insights, it does so fairly specific assumptions. In our view, there are at least two directions in which future research is needed. First, an equilibrium theory of an MFN club in a partial equilibrium model such as ours can only take us so far. A general equilibrium approach such as (Bagwell and Staiger, 1999) to this issue is much needed. Second, we adopt a welfare-maximizing framework and ignore political economy considerations. The

introduction of such considerations in our model might require modifications of some our results.

\section{Appendix}

\subsection{Derivation of optimal tariffs}

Under tariff discrimination, country $i$ solves

$$
\underset{\mathbf{t}_{\mathbf{i}}}{\operatorname{Max}} \frac{x_{i}^{2}\left(\mathbf{t}_{\mathbf{i}}\right)}{2}+x_{i i}^{2}\left(\mathbf{t}_{\mathbf{i}}\right)+\sum_{j \neq i} t_{j i} x_{j i}\left(\mathbf{t}_{\mathbf{i}}\right),
$$


where

$$
x_{i i}=\frac{\alpha-4 \zeta_{i}+Z_{-i}+T_{i}}{5} \text { and } x_{j i}=\frac{\alpha-4\left(\zeta_{j}+t_{j i}\right)+\left(Z_{-j}+T_{-j}\right)}{5}
$$

and

$$
T_{-j}=T_{i}-t_{j i}=\sum_{k \neq j} t_{k i} \text { and } Z_{-i} \equiv Z-\zeta_{i} \text { and } Z \equiv \sum_{j=1}^{4} \zeta_{j} .
$$

Solving the above problem yields

$$
t_{j i}(\phi)=\frac{1}{22}\left[6 \alpha+3 Z-7 \zeta_{i}-11 \zeta_{j}\right]
$$

Under MFN toward all countries, country $i$ solves

$$
\underset{t_{i}}{\operatorname{Max}} S_{i}\left(t_{i}\right) \equiv C S_{i}\left(t_{i}\right)+\pi_{i i}\left(t_{i}\right)+T R_{i}\left(t_{i}\right)
$$

which gives:

$$
t_{i}^{M}=\frac{1}{33}\left[9 \alpha-Z-5 \zeta_{i}\right]
$$

Next we show how optimal tariffs under various MFN clubs are derived. We divide the parameter space into 4 sub-regions:

(i) Region 1 (R1): $\zeta_{b}+\zeta_{d} \leq 2 \zeta_{c}$.

(ii) Region 2 (R2): $2 \zeta_{b} \leq \zeta_{a}+\zeta_{d} \leq 2 \zeta_{c} \leq \zeta_{b}+\zeta_{d}$.

(iii) Region 3 (R3): $\zeta_{a}+\zeta_{d} \leq 2 \zeta_{b} \leq 2 \zeta_{c} \leq \zeta_{b}+\zeta_{d}$.

(iv) Region 4 (R4): $2 \zeta_{b} \leq 2 \zeta_{c} \leq \zeta_{a}+\zeta_{d}$.

As an example consider country $a$ 's tariff problem under $\langle\{a b\}\rangle$ :

$$
\underset{\mathbf{t}_{a}}{M a x} W_{a}\left(\mathbf{t}_{a}\right) \text { subject to } t_{b a}(a b) \leq \min \left\{t_{d a}(a b), t_{c a}(a b)\right\}
$$

Solving the above problem yields:

$$
t_{b a}(a b)=\left\{\begin{array}{cc}
t_{a}^{M} & \mathrm{R} 1 \\
\frac{1}{44}\left(12 \alpha-5 \zeta_{b}+6 \zeta_{c}-5 \zeta_{d}\right) & \text { elsewhere }
\end{array}\right.
$$

whereas

$$
t_{c a}(a b)=\left\{\begin{array}{cc}
t_{a}^{M} & \mathrm{R} 1 \\
\frac{1}{22}\left(6 \alpha+3 \zeta_{b}-8 \zeta_{c}+3 \zeta_{d}\right) & \text { elsewhere }
\end{array}\right.
$$


Similarly, country b's tariffs are

$$
t_{a b}(a b)=\left\{\begin{array}{cc}
\frac{1}{44}\left(12 \alpha-8 \zeta_{b}+6 \zeta_{c}-5 \zeta_{d}\right) & \mathrm{R} 4 \\
t_{b}^{M} & \text { elsewhere }
\end{array}\right.
$$

and

$$
t_{c b}(a b)=\left\{\begin{array}{cc}
\frac{1}{22}\left(-8 \zeta_{c}+3 \zeta_{d}+6 \alpha-4 \zeta_{b}\right) & \mathrm{R} 4 \\
t_{b}^{M} & \text { elsewhere }
\end{array}\right.
$$

Tariffs under $\langle\{a c\}\rangle$ are calculated similarly.

\subsection{Lemma 1}

Total tariff protection by country $i$ is:

$$
T_{i} \equiv \sum_{j \neq i} t_{j i}=\frac{9 \alpha-Z-5 \zeta_{i}}{11}
$$

From Result 2, $T_{i}$ under any MFN club is the same as that under $\langle\{\phi\}\rangle$. Direct computations show that $T_{i} \geq T_{k}$ iff $\zeta_{i} \leq \zeta_{k}$.

\subsection{Lemma 2}

It is straightforward that

$$
t_{b a}(a b c)-t_{b a}(\phi)=\frac{2 \zeta_{b}-\left(\zeta_{c}+\zeta_{d}\right)}{6}<0
$$

whereas

$$
t_{c a}(a b c)-t_{c a}(\phi)=\frac{2 \zeta_{c}-\left(\zeta_{b}+\zeta_{d}\right)}{6}<0 \text { iff } 2 \zeta_{c}<\zeta_{b}+\zeta_{d}
$$

Similar conclusions can be drawn about tariffs of countries $b$ and $c$. We have:

$$
t_{a b}(a b c)<t_{a b}(\phi) \text { whereas } t_{c b}(a b c)<t_{c b}(\phi) \text { iff } 2 \zeta_{c}<\zeta_{d}
$$

and

$$
t_{a c}(a b c)<t_{a c}(\phi) \text { whereas } t_{b c}(a b c)<t_{b c}(\phi) \text { iff } 2 \zeta_{b}<\zeta_{d}
$$

Now consider $\langle\{a b\}\rangle$. When $2 \zeta_{c}<\zeta_{d}$ we can show that:

$$
t_{b a}(a b)-t_{b a}(\phi)=\frac{1}{4}\left(\zeta_{b}-\zeta_{d}\right)<0 \text { and } t_{a b}(a b)-t_{b a}(\phi)=-\frac{\zeta_{d}}{4}<0
$$


whereas $t_{c a}(a b)=t_{b a}(\phi)$ and $t_{c b}(a b)=t_{c b}(\phi)$. When $\zeta_{d}<2 \zeta_{c}<\zeta_{b}+\zeta_{d}$, we have

$$
t_{b a}(a b)-t_{b a}(\phi)=-\frac{1}{4}\left(\zeta_{d}-\zeta_{b}\right)<0 \text { and } t_{a b}(a b)-t_{a b}(\phi)=-\frac{1}{6}\left(\zeta_{c}+\zeta_{d}\right)<0
$$

whereas

$$
t_{c a}(a b)=t_{c a}(\phi) \text { and } t_{c b}(a b)-t_{c b}(\phi)=\frac{1}{6}\left(2 \zeta_{c}-\zeta_{d}\right)>0
$$

Finally when $2 \zeta_{c}>\zeta_{b}+\zeta_{d}$, we have

$$
t_{b a}(a b)-t_{b a}(\phi)=\frac{1}{6}\left(2 \zeta_{b}-\zeta_{c}-\zeta_{d}\right)<0 \text { and } t_{a b}(a b)-t_{a b}(\phi)=-\frac{1}{6}\left(\zeta_{c}+\zeta_{d}\right)<0
$$

whereas

$$
t_{c a}(a b)-t_{c a}(\phi)=\frac{1}{6}\left(2 \zeta_{c}-\zeta_{d}-\zeta_{b}\right)>0 \text { and } t_{c b}(a b)-t_{c b}(\phi)=\frac{1}{6}\left(2 \zeta_{c}-\zeta_{d}\right)>0 .
$$

The analysis under $\langle\{a c\}\rangle$ is analogous to that of $\langle\{a b\}\rangle$ with the roles of countries $b$ and $c$ reversed. However, we only need to consider two cases: $(i) 2 \zeta_{b}<$ $\zeta_{d}$ and $(i i) 2 \zeta_{b}>\zeta_{d}$. Under both cases, member countries receive concessions from each other. Under case $(i)$, tariffs on country $b$ are the same as that under $\langle\{\phi\}\rangle$ whereas under case $(i i)$, it suffers a tariff increase in $c$ 's market with the tariff in $a$ 's market staying the same as that under $\langle\{\phi\}\rangle$. Finally, under $\langle\{b c\}\rangle$ members receive concessions from each other whereas non-members face the same tariffs as that under $\langle\{\phi\}\rangle$.

\subsection{Lemma 3}

Consider $\langle\{a b\}\rangle$. We have:

$$
\Delta t_{a b}(a b)-\Delta t_{b a}(a b)=\left\{\begin{array}{cc}
\frac{\zeta_{b}}{3} \geq 0 & \mathrm{R} 1 \\
\frac{2 \zeta_{c}-\zeta_{d}+3 \zeta_{b}}{a b} \geq 0 & \mathrm{R} 2-\mathrm{R} 3 \\
\frac{\zeta_{b}}{4} \geq 0 & \mathrm{R} 4
\end{array}\right.
$$

Under $\langle\{a c\}\rangle$ we have:

$$
\Delta t_{a c}(a c)-\Delta t_{c a}(a c)=\left\{\begin{array}{cc}
\frac{\zeta_{c}}{4} \geq 0 & \mathrm{R} 1, \mathrm{R} 2, \text { and R4 } \\
\frac{2 \zeta_{b}-\zeta_{d}+3 \zeta_{c}}{a b} \geq 0 & \mathrm{R} 3
\end{array}\right.
$$


and for $\langle\{b c\}\rangle$ we have:

$$
\Delta t_{b c}(b c)-\Delta t_{c b}(b c)=\frac{\zeta_{c}-\zeta_{b}}{4} \geq 0
$$

Finally, under $\langle\{a b c\}\rangle$ we have

$$
\Delta t_{a b}(a b c)-\Delta t_{b a}(a b c)=\frac{\zeta_{b}}{3} \geq 0 \text { and } \Delta t_{a c}(a b c)-\Delta t_{c a}(a b c)=\frac{\zeta_{c}}{3} \geq 0
$$

and

$$
\Delta t_{b c}(a b c)-\Delta t_{c b}(a b c)=\frac{\zeta_{c}-\zeta_{b}}{3} \geq 0
$$

\subsection{Proposition 1}

For $\langle\{a b\}\rangle$ we have:

$\Delta T R_{a}(a b)-\Delta T R_{b}(a b)=\left\{\begin{array}{cc}\frac{1}{6} \zeta_{b}\left(\zeta_{b}-\zeta_{c}-\zeta_{d}\right) \leq 0 & \mathrm{R} 1 \\ \frac{1}{24}\left(4 \zeta_{c} \zeta_{d}-6 \zeta_{b} \zeta_{d}-\zeta_{d}^{2}-4 \zeta_{c}+3 \zeta_{b}\right) \leq 0 & \mathrm{R} 2 \text { and R3 }\end{array}\right.$

Under $\langle\{a c\}\rangle$ we have:

$\Delta T R_{a}(a c)-\Delta T R_{c}(a c)=\left\{\begin{array}{c}\frac{1}{8} \zeta_{c}\left(-2 \zeta_{d}+\zeta_{c}\right) \leq 0 \\ \frac{1}{24}\left(4 \zeta_{b} \zeta_{d}-\zeta_{d}^{2}+3 \zeta_{c}-6 \zeta_{c} \zeta_{d}-4 \zeta_{b}\right) \leq 0\end{array}\right.$

$\mathrm{R} 1, \mathrm{R} 2$, and $\mathrm{R} 4$

whereas under $\langle\{b c\}\rangle$ we have:

$$
\Delta T R_{b}(b c)-\Delta T R_{c}(b c)=\frac{1}{8}\left(\zeta_{c}-\zeta_{b}\right)\left(\zeta_{b}-2 \zeta_{d}+\zeta_{c}\right) \leq 0
$$

Finally, under $\langle\{a b c\}\rangle$ we have:

$$
\Delta T R_{a}(a b c)-\Delta T R_{b}(a b c)=\frac{1}{6} \zeta_{b}\left(\zeta_{b}-\zeta_{c}-\zeta_{d}\right) \leq 0
$$

and

$$
\Delta T R_{a}(a b c)-\Delta T R_{c}(a b c)=\frac{1}{6} \zeta_{c}\left(\zeta_{c}-\zeta_{d}-\zeta_{b}\right) \leq 0
$$




\subsection{Lemma 4}

From country a's perspective:

$$
\Delta T R_{a}(a c)-\Delta T R_{a}(a b)=\left\{\begin{array}{cc}
-\frac{1}{24}\left(2 \zeta_{b}-\zeta_{c}-\zeta_{d}\right)^{2} \leq 0 & \mathrm{R} 1 \\
-\frac{1}{8}\left(\zeta_{b}-\zeta_{c}\right)\left(-2 \zeta_{d}+\zeta_{b}+\zeta_{c}\right) \leq 0 & \mathrm{R} 2-\mathrm{R} 4
\end{array}\right.
$$

For country $b$ we have:

$$
\Delta T R_{b}(b c)-\Delta T R_{b}(a b)=\left\{\begin{array}{cc}
-\frac{1}{24}\left(\zeta_{c}+\zeta_{d}\right)^{2} \leq 0 & \mathrm{R} 1-\mathrm{R} 3 \\
-\frac{1}{8} \zeta_{c}\left(2 \zeta_{d}-\zeta_{c}\right) \leq 0 & \mathrm{R} 4
\end{array}\right.
$$

Finally, for country $c$ we have:

$$
\Delta T R_{c}(b c)-\Delta T R_{c}(a c)=\left\{\begin{array}{cc}
-\frac{1}{8} \zeta_{b}\left(2 \zeta_{d}-\zeta_{b}\right) \leq 0 & \mathrm{R} 1, \mathrm{R} 2, \text { and } \mathrm{R} 4 \\
-\frac{1}{24}\left(\zeta_{b}+\zeta_{d}\right)^{2} \leq 0 & \mathrm{R} 3
\end{array}\right.
$$

Hence $\Delta T R_{i}(i k)-\Delta T R_{i}(i j) \leq 0$ iff $\zeta_{j} \leq \zeta_{k}$ for all $i, j, k$.

\subsection{Lemma 5}

Note that

$$
\Delta t_{a c}-\Delta t_{a b}=\left\{\begin{array}{cc}
\frac{\zeta_{d}-2 \zeta_{c}}{{ }_{6}{ }^{6}} \leq 0 & \mathrm{R} 1-\mathrm{R} 2 \\
\frac{\zeta_{b}}{6} \leq 0 & \mathrm{R} 3 \\
0 & \mathrm{R} 4
\end{array}\right.
$$

Also,

$$
\Delta t_{b c}-\Delta t_{b a}=\left\{\begin{array}{cc}
\frac{\zeta_{b}+\zeta_{d}-2 \zeta_{c}}{12} \leq 0 & \mathrm{R} 1 \\
0 & \mathrm{R} 2-\mathrm{R} 4
\end{array}\right.
$$

Finally note that $\Delta t_{c b}-\Delta t_{c a}=0$.

\subsection{Equilibria of the OM game}

First note that the only Nash equilibrium from which coalitional deviations need to be examined is $\langle\{a b c\}\rangle$. To see why, imagine any two country club such as $\langle\{a b\}\rangle$ that is a Nash equilibrium. If $\langle\{a b\}\rangle$ is a Nash equilibrium, by definition, no single country would deviate to $\langle\{\phi\}\rangle$. The deviation of both to $\langle\{\phi\}\rangle$ is not credible since country $a$ loses from such a deviation and would not agree to it. By

similar arguments, any two country club that is a Nash equilibrium would also be coalition-proof. 
Now consider $\langle\{a b c\}\rangle$ as a Nash equilibrium. For $\langle\{a b c\}\rangle$ to be coalition-proof when it is Nash, we need to only ask whether a deviation by countries $b$ and $c$ to $\langle\{\phi\}\rangle$ is credible-country $a$ does not ever gain from leaving the club. It turns out that, under conditions specified below, if countries $b$ and $c$ deviate to $\langle\{\phi\}\rangle$ then at least one of them wants to further deviate to form a club with country $a$. As a result, their original deviation to $\langle\{\phi\}\rangle$ is not credible. As a result, if $\langle\{a b c\}\rangle$ is Nash then it is also coalition-proof if $(i)$ if $w_{b}(a b c) \geq w_{b}(a c)$ then $w_{b}(a b) \geq w_{b}(\phi)$; and $(i i)$ if $w_{c}(a b c) \geq w_{c}(a b)$ then $w_{c}(a c) \geq w_{c}(\phi)$. These conditions are minor and are satisfied for the entire parameter space over which Figures 1-4 have been constructed.

\subsection{Proposition 3}

This result follows from direct calculations. As an example, consider country $c$ 's preferences. We have:

$$
w_{c}(b c)-w_{c}(a c)=\left\{\begin{array}{cc}
F \equiv \frac{1}{88}\left(-\zeta_{b}\right)\left(11 \zeta_{b}+10 \zeta_{c}-32 \zeta_{d}\right) \geq 0 & \mathrm{R} 1, \mathrm{R} 2, \text { and R4 } \\
=F+1 / 24\left(\zeta_{d}-2 \zeta_{b}\right)^{2} \geq 0 & \mathrm{R} 3
\end{array}\right.
$$

Similar calculations underlie the other rankings and we do not report the formulae to conserve space.

\subsection{Proposition 4}

Direct computations give:

$$
\Delta w w(b c) \equiv w w(b c)-w w(\phi)=\frac{1}{4}\left[\left(\zeta_{d}-\zeta_{b}\right)^{2}+\left(\zeta_{d}-\zeta_{c}\right)^{2}\right] \geq 0 .
$$

Similarly,

$$
w w(a c)-w w(b c)=\left\{\begin{array}{cc}
\frac{1}{12}\left(-\zeta_{d}-\zeta_{b}\right)^{2} \geq 0 & \mathrm{R} 3 \\
\frac{1}{4}\left(-\zeta_{b}\right)\left(\zeta_{b}-2 \zeta_{d}\right) \geq 0 & \text { elsewhere }
\end{array}\right.
$$

and

$$
w w(a b)-w w(a c)=\left\{\begin{array}{cc}
K \equiv \frac{1}{4}\left(-\zeta_{c}+\zeta_{b}\right)\left(-2 \zeta_{d}+\zeta_{b}+\zeta_{c}\right) \geq 0 & \mathrm{R} 4 \\
K+\frac{1}{12}\left(-2 \zeta_{c}+\zeta_{d}\right)^{2} \geq 0 & \mathrm{R} 1 \\
L \equiv \frac{1}{12}\left(-\zeta_{c}+\zeta_{b}\right)\left(-\zeta_{b}-2 \zeta_{d}-\zeta_{c}\right) \geq 0 & \mathrm{R} 2 \\
L+\frac{1}{12}\left(\zeta_{d}-2 \zeta_{b}\right)^{2} \geq 0 & \mathrm{R} 3
\end{array}\right.
$$


Finally,

$$
w w(a b c)-w w(a b)=\left\{\begin{array}{cc}
P \equiv \frac{1}{3}\left(\zeta_{d}-\frac{1}{2} \zeta_{b}\right)^{2}+\frac{1}{4}\left(\zeta_{b}\right)^{2} \geq 0 & \mathrm{R} 1 \\
Q \equiv P+\frac{1}{12}\left(\zeta_{d}+\zeta_{b}-2 \zeta_{c}\right)^{2} \geq 0 & \mathrm{R} 2-\mathrm{R} 3 \\
Q+\frac{1}{12}\left(-2 \zeta_{c}+\zeta_{d}\right)^{2} \geq 0 & \mathrm{R} 4
\end{array}\right.
$$

Thus, we have shown that in every region

$$
\Delta w w(a b c) \geq \Delta w w(a b) \geq \Delta w w(a c) \geq \Delta w w(b c) \geq 0 .
$$

\section{References}

[1] Aghion, P., P. Antràs, E. Helpman, 2004. Negotiating free trade. NBER Working Paper 10721.

[2] Bagwell, K., Staiger, R.W., 1999. An economic theory of GATT. American Economic Review 89, 215-248.

[3] Bagwell, K., Staiger, R.W., 2004. Multilateral trade negotiations, bilateral opportunism and the rules of GATT/WTO. Journal of International Economics 63, 1-29.

[4] Bernheim, B. D., B. Peleg, and M. D. Whinston, 1987a. Coalition-proof Nash equilibria: I concepts. Journal of Economic Theory 42, 1-12.

[5] Brander, J. A., Krugman, P.R., 1983. A 'reciprocal dumping' model of international trade. Journal of International Economics 15, 313-323.

[6] Brander, J. A., Spencer, B. J., 1984. Tariff protection and imperfect competition. In ed. H. Kierzkowski Monopolistic Competition and International Trade. Oxford University Press, New York, NY.

[7] Burbidge, J. B., J. A. DePater, G. M. Myers, and A. Sengupta, 1997. A coalition-formation approach to equilibrium federations and trading blocs. American Economic Review 87, 940-956.

[8] Caplin, A., Krishna, K., 1988. Tariffs and the most favored nation clause: a game theoretic approach. Seoul Journal of Economics 1, 267-289. 
[9] Choi, J. P., 1995. Optimal tariffs and the choice of technology: discriminatory tariffs vs. the most favored nation clause. Journal of International Economics $38,143-160$.

[10] Dutta, B., Mutuswami, S., 1997. Stable networks. Journal of Economic Theory $76,322-344$.

[11] Ederington, J., McCalman, P., 2003. Discriminatory tariffs and international negotiations. Journal of International Economics 61, 397-424.

[12] Gatsios, K., 1990. Preferential tariffs and the 'most favoured nation' principle: a note. Journal of International Economics 28, 365-373.

[13] Hart, S. Kurz, M., 1983. Endogenous formation of coalitions. Econometrica 51, 1047-64.

[14] Horn, H., Mavroidis, P. C., 2001. Economic and legal aspects of the mostfavored nation clause. European Journal of Political Economy 17, 233-279.

[15] Hwang H., Mai, C.-C, 1991. Optimum discriminatory tariffs under oligopolistic competition. Canadian Journal of Economics XXIV, 693-702.

[16] Irwin, D. A., 2002. Free Trade under Fire. Princeton University Press, Princeton.

[17] Jackson, J. H., 1997. The World Trading System. The MIT Press, Cambridge.

[18] Ludema, R., 1991. International trade bargaining and the most-favorednation clause. Economics and Politics 3, 1-20.

[19] Maggi, G., 1999. The role of multilateral institutions in international trade cooperation. American Economic Review 89, 190-214.

[20] McCalman, P., 2002. Multi-lateral trade negotiations and the most favored nation clause. Journal of International Economics 27, 151-176.

[21] Oyejide, A. T., 2002. Special and Differential Treatment. In A. Mattoo, B. Hoekman, and P. English, eds., Development, Trade, and the WTO: A Handbook, The World Bank, Washington, D.C. 
[22] Rose, A., 2004a. Do we really know that the WTO increases trade? American Economic Review 94, 98-114.

[23] Rose, A., 2004b. Do WTO members have a more liberal trade policy? Journal of International Economics 63, 209-235.

[24] Saggi, K., 2004. Tariffs and the most favored nation clause. Journal of International Economics 63, 341-368.

[25] Saggi, K., Yildiz, H. M., 2005. An analysis of the MFN clause under asymmetries of cost and market structure. Canadian Journal of Economics 38, $242-254$.

[26] Staiger, R. W., 1995. International rules and institutions for trade policy. In G. M. Grossman and K. Rogoff, eds., The Handbook of International Economics, vol. 3, Elsevier Science, Amsterdam.

[27] Takemori, S., 1994. The most favored nation clause. Keio Economic Studies $31,37-50$.

[28] Tussie, D., Miguel F. L., 2002. Developing countries: turning participation into influence. In A. Mattoo, B. Hoekman, and P. English, eds., Development, Trade, and the WTO: A Handbook, The World Bank, Washington, D.C.

[29] Yi, S.-S., 1996. Endogenous formation of customs unions under imperfect competition: open regionalism is good. Journal of International Economics $41,153-177$. 


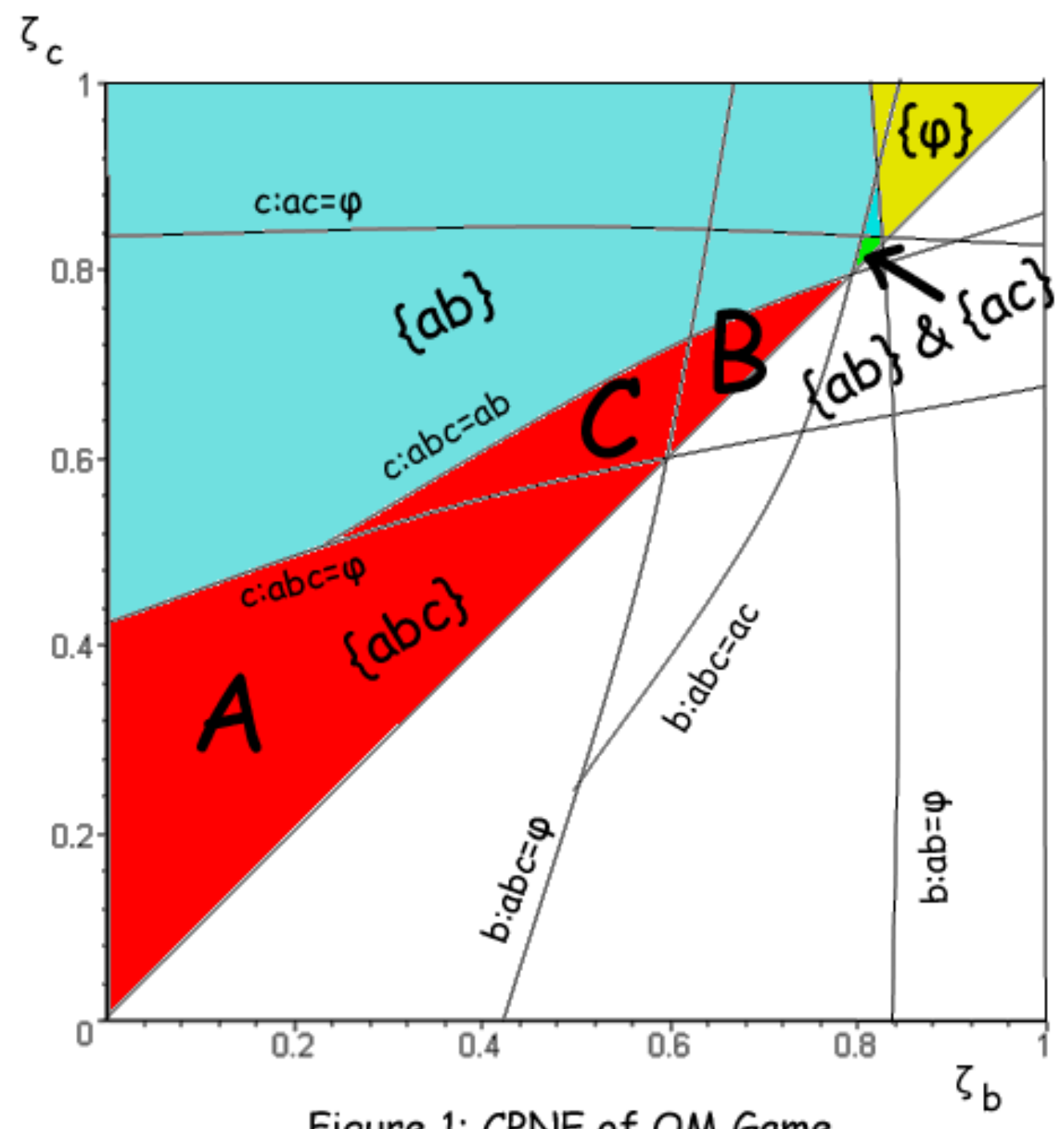

Figure 1: CPNE of OM Game 


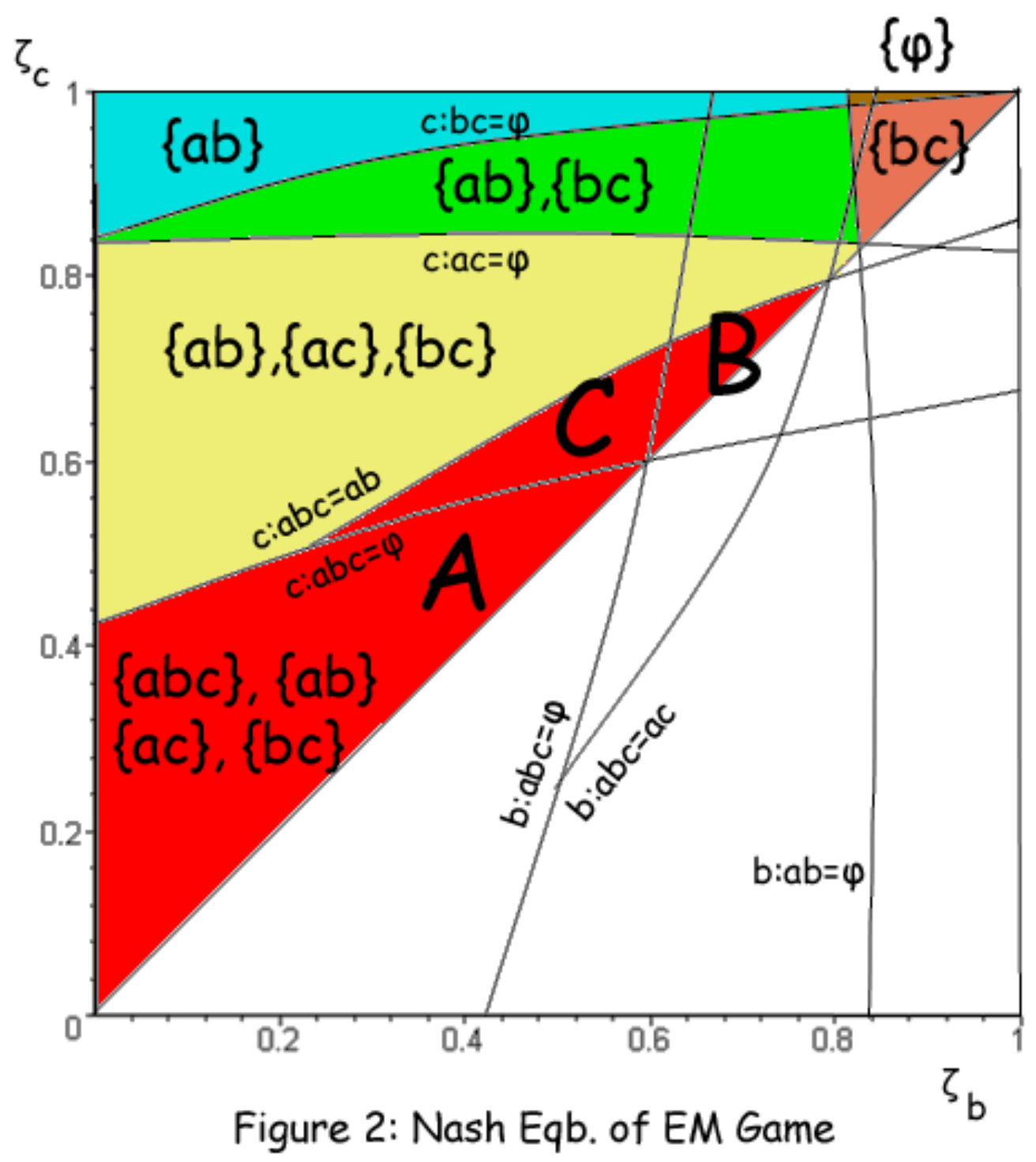




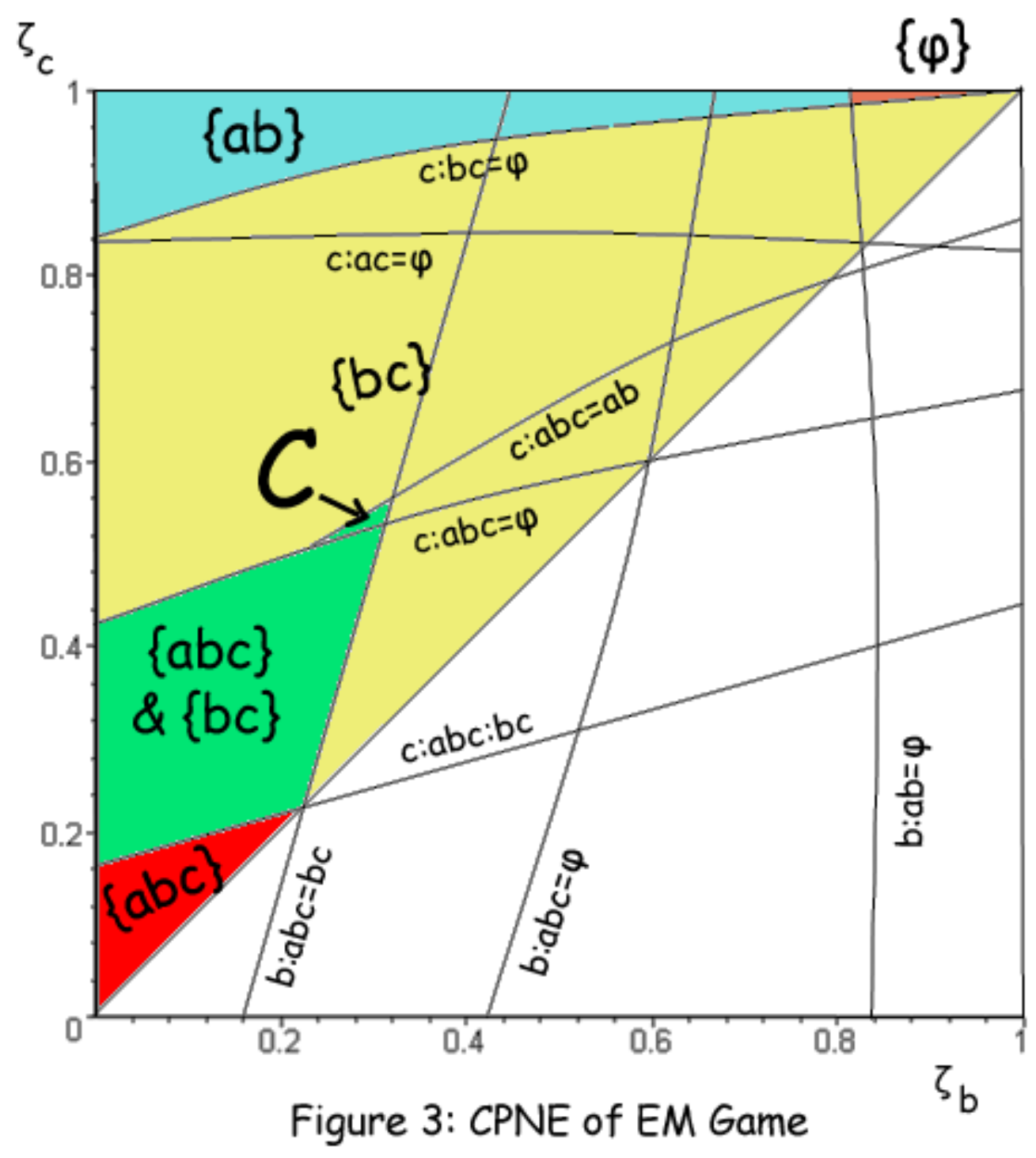




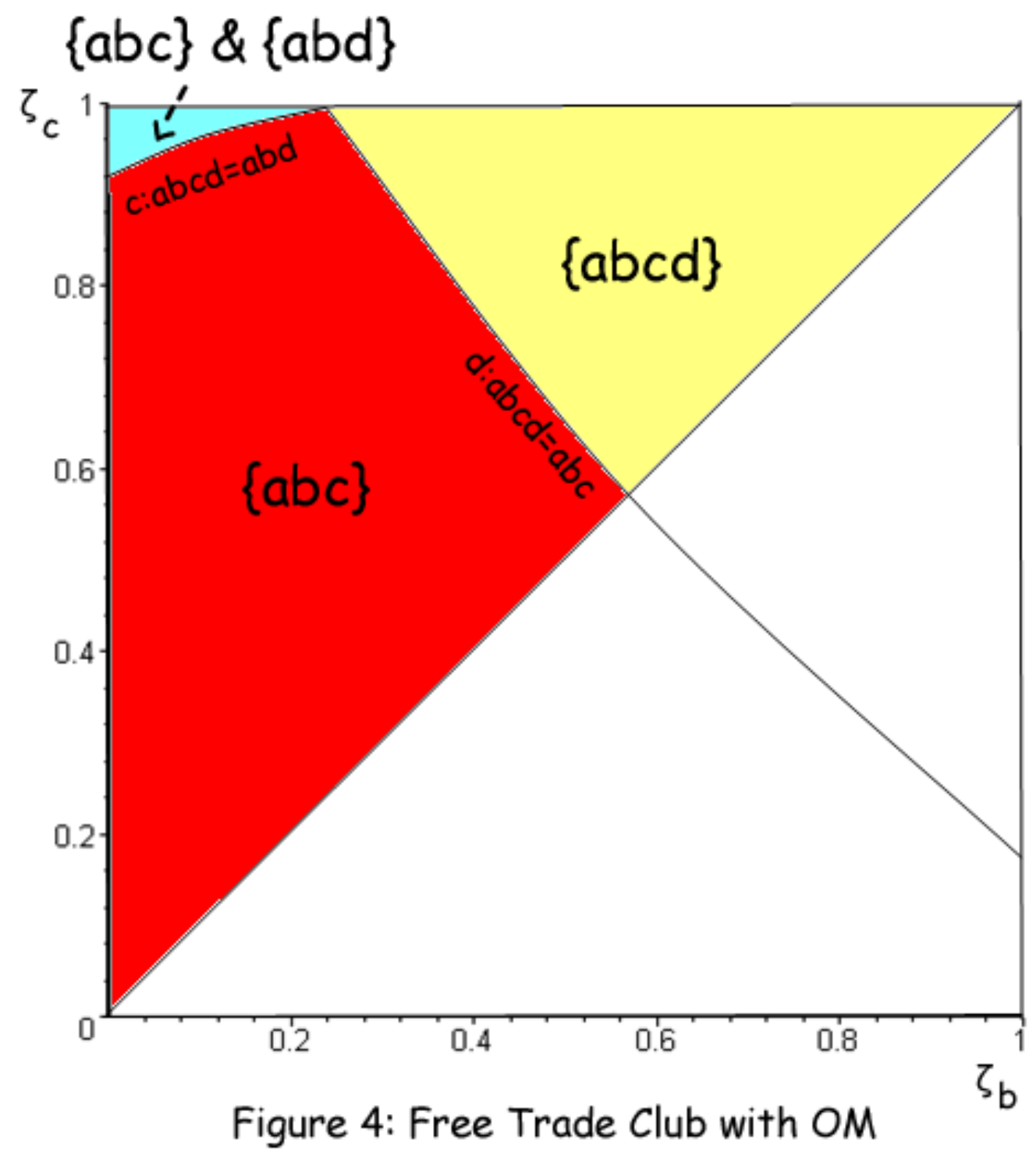

